\title{
Conhecimento e percepção sobre o HPV na população com mais de 18 anos da cidade de Ipatinga, MG, Brasil
}

\author{
Knowledge and perception of HPV in the population over 18 years \\ of age in the city of Ipatinga - State of Minas Gerais, Brazil
}

\author{
Mery Natali Silva Abreu ${ }^{1}$ \\ Angela Deise Soares ${ }^{2}$ \\ Diemack Alle Oliveira Ramos ${ }^{2}$ \\ Fernanda Vieira Soares ${ }^{2}$ \\ Gerson Nunes Filho ${ }^{2}$ \\ Analina Furtado Valadão ${ }^{2}$ \\ Patrícia Gonçalves da Motta ${ }^{2}$
}

${ }^{1}$ Departamento de Enfermagem Aplicada, Escola de Enfermagem, Universidade Federal de Minas Gerais. Av. Alfredo Balena 190/336, Santa Efigênia. 31130-100 Belo Horizonte MG Brasil. merynatali@yahoo.com.br ${ }^{2}$ Curso de Medicina, Instituto Metropolitano de Ensino Superior. Ipatinga MG Brasil.

\begin{abstract}
Several studies have identified misconceptions about human papillomavirus (HPV), which can lead to negligent behavior and risk to the health of the population. This article aims to assess the knowledge of men and women about $H P V$ in the city of Ipatinga, Minas Gerais, and evaluate socioeconomic factors and preventive measures associated with such knowledge. It involved a cross-sectional study with 591 subjects living in the city, by means of stratified sampling by quotas proportional to the number of individuals by sex and age in each of the eight administrative regions of the city. Pearson's chi-square test or the t-Student test and the binary logistic regression model were used to assess the factors associated with knowledge about HPV. Less than half $(40.1 \%)$ of the respondents said they knew what HPV was. Factors associated with having knowledge about HPV were being female, having secondary or tertiary education, using the private health service, having heard about or seen a campaign about HPV and knowing of the existence of a vaccine against HPV. There is a great deficit of knowledge about HPV and vague information of what is known, favoring actions with a potential risk to personal health, including that of the partner.
\end{abstract}

Key words HPV, STD, Knowledge
Resumo Vários estudos têm identificado conceitos errôneos sobre o Papiloma Virus Humano (HPV), o que pode propiciar comportamentos negligentes e de risco para a saúde da população. $O$ objetivo deste artigo é avaliar o conhecimento de homens e mulheres acerca do HPV na população do município de Ipatinga-MG, além de avaliar os fatores socioeconômicos e as atitudes preventivas associadas a esse conhecimento. Estudo transversal, com 591 indivíduos residentes na cidade de Ipatinga, por meio de amostragem estratificada por quotas, proporcional ao número de indivíduos por sexo e idade em cada uma das oito regionais administrativas da cidade. Para avaliar os fatores associados ao conhecimento sobre HPV foram utilizados os testes qui-quadrado ou t-Student e modelo de regressão logística binária. Menos da metade $(40,1 \%)$ dos entrevistados afirmaram saber o que é HPV. Os fatores associados ao relato de conhecimento sobre HPV foram: ser do sexo feminino, ter nível de escolaridade médio ou superior, utilizar o serviço de saúde particular, ter ouvido ou visto alguma campanha sobre HPV e saber da existência da vacina contra o HPV. Existe grande déficit de conhecimento sobre o HPV e pouca qualificação do que se sabe, favorecendo ações com risco potencial à saúde, inclusive do parceiro.

Palavras-chave HPV,DST, Conhecimento 


\section{Introdução}

A infecção pelo Papiloma Vírus Humano (HPV) é uma das doenças sexualmente transmissíveis (DST) mais frequentes no mundo ${ }^{1}$. Estima-se que entre 75 a $80 \%$ da população será acometida por pelo menos um dos tipos do HPV ao longo da vida ${ }^{2}$. Mais de 630 milhões de homens e mulheres (1:10 pessoas) estão infectados. Para o Brasil, estima-se que haja 9 a 10 milhões de infectados por esse vírus e que, a cada ano, 700 mil novos casos ocorram ${ }^{3}$.

O HPV é um vírus de DNA, já descritos mais de 200 tipos, agrupados pelo potencial oncogênico. Aproximadamente 45 tipos infectam o epitélio do trato anogenital masculino e feminino ${ }^{3}$. Segundo o Manual de Controle das Doenças Sexualmente Transmissíveis (DST), de 2006, podem ser classificados como de baixo risco (tipos $6,11,42,43$ e 44 ) e de alto risco (tipos 16, 18, 31, $33,35,39,45,46,51,52,56,58,59$ e 68$)$. No mundo, cerca de 105 milhões de pessoas são positivas para o HPV 16 ou $18^{3}$. É atribuído potencial oncogênico para alguns tipos de cânceres de colo de útero (carcinoma espinocelular), vulva e vagina, pênis, ânus, laringe, faringe e cavidade oral ${ }^{4}$.

A infecção decorre principalmente do contato sexual sem proteção, que permite, por meio de microabrasões, a penetração do vírus na camada profunda do tecido epitelial. Entretanto pode-se dar pelo contato direto ou indireto com as lesões em outras partes do corpo ${ }^{5}$. Ainda é descrita a transmissão vertical durante a gestação ou no momento do parto. As lesões apresentam-se na forma de verruga comum, verruga genital ou condiloma, popularmente conhecida como "crista de galo". O diagnóstico clínico se dá pela presença de lesões únicas ou múltiplas, granulares e verrugosas ${ }^{5}$. É assintomática na maioria das vezes e, quando presente, inclui prurido, hiperemia variável e descamação local. A técnica do Papanicolau é o exame que identifica as alterações celulares por ele induzidas no colo de útero, sendo indicado na rotina de rastreio para o câncer cervical ${ }^{4,6}$.

Existem alguns fatores envolvidos no risco de infecção: comportamento sexual de risco, início precoce da vida sexual, número de parceiros sexuais, higiene genital inadequada, alterações da imunidade celular, ausência da circuncisão masculina, tabagismo e presença de outras DSTs ${ }^{3,7-10}$.

Em decorrência da veiculação de informações acerca da incidência de DST, vem ocorrendo um aumento do uso de preservativos entre jovens em geral. Entretanto, apesar do conhecimento entre os jovens de que o HPV pode se desenvolver em ambos os sexos, a maioria pensa que as complica- ções são mais graves e a incidência é maior entre as mulheres ${ }^{11}$. Entre universitários na Colômbia, apenas cerca de $32 \%$ dos estudantes possuíam nível de conhecimento médio sobre o tema, tornando essa população susceptível à exposição e transmissão do vírus ${ }^{12}$. Em torno de $20 \%$ das mulheres infectadas omitiam essa informação do parceiro devido à falta de apoio, a acusações de traições e a reações grosseiras ${ }^{13}$. Há necessidade de as mulheres acessarem conhecimento e entender a doença, pois o desconhecimento dificulta tomadas de decisão, agravadas por fatores emocionais $^{14}$. Entre adolescentes chilenas, mais da metade afirmou que o câncer de colo uterino é diagnosticado mediante exame de sangue e, para $70 \%$, pelo exame de urina. Cerca de 60,6\% apontaram a hereditariedade como fator de risco para infecção; e para apenas $47,8 \%$, a transmissão poderia ocorrer por contato sexual, sem penetração e sem proteção ${ }^{15}$.

É perspicaz a indagação de que o nível de conhecimento influencie na utilização de métodos preventivos para o HPV, tornando-se importante fator na interrupção dessa morbidade. Dessa forma, pode ser útil na elaboração de políticas públicas de saúde para combate às DSTs, uma maior ênfase na informação segundo a peculiaridade de cada grupo social.

O objetivo deste estudo foi avaliar o conhecimento de homens e mulheres acerca do vírus HPV na população de um município do interior de Minas Gerais, além de avaliar os fatores socioeconômicos e atitudes preventivas associadas a esse conhecimento.

\section{Métodos}

Estudo descritivo, com delineamento transversal, realizado no município de Ipatinga, no ano de 2014. Ipatinga é uma das cidades que compõem a região metropolitana do Vale do Aço, localizada no leste do estado de Minas Gerais. De acordo com o censo demográfico de 2010, a cidade possui um total de 239.177 habitantes e, desses, $51,47 \%$ são do gênero feminino ${ }^{16}$. A maioria da população encontra-se distribuída nas idades entre 15 e 34 anos e residentes em zona urbana. A economia do município está ancorada na indústria, e um pequeno percentual vem da agropecuária, mas ainda possui a colaboração da área de turismo de negócios. Ipatinga conta com hospitais bem estruturados, Unidades de Pronto Atendimento e vários centros de atenção primária, que servem inclusive como apoio às cidades adjacentes ${ }^{17}$. 
O tamanho da amostra considerou uma população total de 174.363 indivíduos (com 18 anos ou mais), residentes na área urbana da cidade de Ipatinga-MG, segundo censo de 2010. Para um nível de significância de $5 \%$, poder de $80 \%$ e precisão de $4 \%$, estimou-se uma amostra de aproximadamente 600 indivíduos (Open Epi versão 3.01). A metodologia utilizada foi de amostragem estratificada por quotas ${ }^{18}$. As quotas tiveram distribuição proporcional ao número de indivíduos por sexo e idade em cada uma das nove regionais administrativas da cidade ${ }^{17}$. Além disso, foram coletados dados no território de cada uma dessas regionais, com número de entrevistados proporcional ao número de habitantes da regional, visando garantir representatividade da população do município. Durante a análise dos dados, a regional 9 foi agrupada à 5 , em virtude de um 'n' amostral baixo e pela proximidade geográfica.

A abordagem para coleta de dados realizada foi de forma verbal, por meio de formulários estruturados, em ambientes públicos e/ou privados da cidade de Ipatinga - MG, com indivíduos que residiam nos bairros previamente estabelecidos na amostragem. Os formulários foram pré-testados em uma amostra de cerca de 50 pessoas residentes em um dos bairros da cidade e revisados conforme surgiam eventuais problemas de compreensão ou preenchimento. A coleta dos dados foi realizada no período de junho a agosto de 2014. Durante a coleta dos dados, houve recusa de participação por 17 sujeitos abordados e foram descartados 9 formulários de indivíduos que pertenciam a outro município vizinho, totalizando uma amostra de 591 entrevistados.

A variável desfecho do estudo foi ter afirmado saber ou não o que é HPV. Para verificar a validade dessa variável, foi utilizada uma metodologia proposta por Osis et al. ${ }^{19}$, nomeada neste estudo como "conhecimento mínimo" sobre HPV. Possuiria "conhecimento mínimo" sobre o tema o entrevistado que afirmasse saber o que é HPV e que também informasse pelo menos uma das assertivas: que "é uma DST", que "pode causar câncer" ou que "pode provocar verruga/condiloma".

Foram consideradas como variáveis explicativas características sociodemográficas e questões relacionadas às práticas preventivas.

As variáveis sociodemográficas estudadas foram gênero, regional/bairro, religião, escolaridade, estado civil, serviço de saúde, idade, número de filhos, renda familiar.

As variáveis utilizadas para caracterizar o conhecimento sobre HPV foram meio de comunicação por onde soube a maioria das informações, saber e citar a(s) forma(s) de transmissão, quem pode pegar (homem/mulher/criança), saber da transmissão vertical da infecção. Já as variáveis relacionadas às atitudes preventivas foram saber da existência de vacina, ter visto ou ouvido alguma campanha de HPV e/ou DST, fazer ou ter intenção de uso do preservativo, ter realizado o Papanicolaou/Citopatológico/Preventivo (apenas para mulheres).

Os dados coletados foram agrupados no banco de dados por meio do programa Epi-info versão 7.0 e analisados no programa SPSS versão 15.0. Para análise descritiva dos dados, foram utilizadas tabelas de distribuição de frequências e medidas de tendência central e variabilidade. Para avaliar os fatores associados ao conhecimento sobre HPV, foram utilizados, na análise univariada, os testes qui-quadrado de Pearson ou t-Student. $\mathrm{Na}$ análise multivariada, foi utilizado o modelo de regressão logística binária. Para entrada no modelo, foram consideradas as variáveis com valor-p menor que 0,20 , na análise univariada. Foi utilizado o método backward com retirada das variáveis do modelo uma a uma. Para permanência da variável no modelo final, foi considerado um nível de significância de 5\%, assim como nas demais análises realizadas.

A pesquisa foi aprovada pelo Comitê de Ética em Pesquisa do Centro Universitário do Leste de Minas Gerais - Unileste. A participação na pesquisa se deu de forma voluntária, tendo sido necessária a assinatura do termo de consentimento livre e esclarecido (TCLE). Os formulários não possuíam dados que permitissem identificar o sujeito, sendo garantido o anonimato.

\section{Resultados}

De acordo com os resultados (Tabela 1), observou-se que menos da metade $(40,1 \%)$ dos entrevistados afirmaram saber o que é HPV e, desses, 93,25\% têm um conhecimento mínimo sobre a doença. A maioria das informações sobre o assunto foi obtida via TV $(47,3 \%)$, seguidas de professores $(25,3 \%)$ e pela internet $(24,1 \%)$. Dentre aqueles que asseguraram ter conhecimento sobre o HPV, 97,3\% garantiram que a relação sexual é uma forma de transmissão, enquanto apenas $10 \%$ indicaram o contato com a lesão. Por meio de objetos contaminados e transfusão sanguínea foram opções relatadas por 14\% e 11,8\% dos entrevistados, respectivamente.

A maioria dos indivíduos questionados (96,6\%), responderam que mulheres podem contrair HPV, enquanto os que responderam que 
Tabela 1. Caracterização da percepção sobre HPV entre moradores da cidade de Ipatinga (2014).

\begin{tabular}{|c|c|c|}
\hline & Frequência & Percentual (\%) \\
\hline \multicolumn{3}{|c|}{ Você sabe o que é HPV?(n = 591) } \\
\hline Não & 354 & 59,9 \\
\hline $\operatorname{Sim}$ & 237 & 40,1 \\
\hline \multicolumn{3}{|c|}{ Conhecimento Mínimo sobre HPV $(\mathrm{n}=237)$} \\
\hline $\operatorname{Sim}$ & 221 & 93,25 \\
\hline Não & 16 & 6,75 \\
\hline \multicolumn{3}{|c|}{$\begin{array}{l}\text { Por qual meio de comunicação você obteve a maioria das informações } \\
\text { sobre o HPV? }(\mathrm{n}=237)\end{array}$} \\
\hline TV & 112 & 47,3 \\
\hline Professores & 60 & 25,3 \\
\hline Internet & 57 & 24,1 \\
\hline Cartaz/folder/folheto & 31 & 13,1 \\
\hline Profissionais de saúde & 30 & 12,7 \\
\hline Amigos & 28 & 11,8 \\
\hline Médicos & 24 & 10,1 \\
\hline Jornal/Revista & 22 & 9,3 \\
\hline Rádio & 8 & 3,4 \\
\hline Outros meios ${ }^{\star}$ & 25 & 10,5 \\
\hline \multicolumn{3}{|c|}{ Sabe qual a forma de transmissão do HPV? $(\mathrm{n}=237)$} \\
\hline Não & 16 & 6,8 \\
\hline $\operatorname{Sim}$ & 221 & 93,2 \\
\hline \multicolumn{3}{|l|}{ Quais? $(\mathrm{n}=221)$} \\
\hline Relação Sexual & 215 & 97,3 \\
\hline Objetos & 31 & 14,0 \\
\hline Transfusão Sanguínea & 26 & 11,8 \\
\hline Contato com a lesão & 22 & 10,0 \\
\hline Beijo & 13 & 5,9 \\
\hline Materno-fetal & 6 & 2,7 \\
\hline Ar & 3 & 1,4 \\
\hline Outras formas & 4 & 1,8 \\
\hline \multicolumn{3}{|c|}{ Quem pode pegar HPV? $(\mathrm{n}=237)$} \\
\hline Homens & 194 & 81,9 \\
\hline Mulheres & 229 & 96,6 \\
\hline Crianças & 97 & 40,9 \\
\hline Não sabe & 8 & 3,4 \\
\hline
\end{tabular}

* Experiência própria, filho(a), esposa.

homens e crianças poderiam contrair o vírus foram $81,9 \%$ e $40,9 \%$, respectivamente.

Mais da metade das pessoas pesquisadas $(56,5 \%)$ relatou acreditar que o bebê pode contrair o HPV durante a gestação, enquanto 30\% não souberam responder se poderia ou não.

O gênero feminino (Tabela 2) prevaleceu entre os entrevistados (52,3\%), sendo esse grupo o que apresentou maior percentual dos que sabiam o que era o HPV $(46,9 \%)$ (valor-p $<0,001)$.

Dentre as regionais, observou-se que a regional 1 apresentou maior percentual de entrevistados que sabiam o que era o HPV (57,9\%), e a regional 4, o menor percentual $(32,5 \%)$.
Os percentuais de protestantes (46,2\%) e católicos $(45,7 \%)$ que participaram da pesquisa foram próximos, e a análise sobre o conhecimento não mostrou diferença significativa entre eles (valor-p $=0,839)$.

Com relação ao nível de escolaridade, a maioria havia cursado o ensino médio (49,6\%), enquanto apenas $17,7 \%$ concluíram o ensino superior. Dentre aqueles com maior nível de escolaridade, mais da metade $(64,8 \%)$ afirmou ter conhecimento sobre o HPV; já entre os que possuíam o ensino médio e o fundamental, esse relato foi de apenas $43,7 \%$ e $21,2 \%$, respectivamente (valor-p $<0,001$ ). 
Tabela 2. Caracterização dos dados sociodemográficos na amostra total e comparados ao conhecimento relatado sobre o HPV entre moradores da cidade de Ipatinga no ano de 2014.

\begin{tabular}{|c|c|c|c|c|}
\hline & \multirow[t]{2}{*}{ Frequência (\%) } & \multicolumn{2}{|c|}{ Você sabe o que é HPV? V? } & \multirow[t]{2}{*}{ Valor-p } \\
\hline & & Não & Sim & \\
\hline Gênero & & & & $<0,001^{\star}$ \\
\hline Masculino & $282(47,7 \%)$ & $190(67,4 \%)$ & $92(32,6 \%)$ & \\
\hline Feminino & $309(52,3 \%)$ & $164(53,1 \%)$ & $145(46,9 \%)$ & \\
\hline Religião & & & & $0,839^{*}$ \\
\hline Católico & $270(45,7 \%)$ & $164(60,7 \%)$ & $106(39,3 \%)$ & \\
\hline Protestante & $273(46,2 \%)$ & $163(59,7 \%)$ & $110(40,3 \%)$ & \\
\hline Outros & $48(8,1 \%)$ & $27(56,3 \%)$ & $21(43,8 \%)$ & \\
\hline Escolaridade & & & & $<0,001^{*}$ \\
\hline Fundamental & $193(32,7 \%)$ & $152(78,8 \%)$ & $41(21,2 \%)$ & \\
\hline Ensino Médio & $293(49,6 \%)$ & $165(56,3 \%)$ & $128(43,7 \%)$ & \\
\hline Superior & $105(17,7 \%)$ & $37(35,2 \%)$ & $68(64,8 \%)$ & \\
\hline Estado civil & & & & $0,033^{*}$ \\
\hline Sem parceiro & $281(47,5 \%)$ & $181(64,4 \%)$ & $100(35,6 \%)$ & \\
\hline Com parceiro & $310(52,5 \%)$ & $173(55,8 \%)$ & $137(44,2 \%)$ & \\
\hline Serviço de saúde utilizado maioria & & & & $<0,001^{\star}$ \\
\hline \multicolumn{5}{|l|}{ na maioria das vezes } \\
\hline Público & $340(57,5 \%)$ & $232(68,2 \%)$ & $108(31,8 \%)$ & \\
\hline Particular & $251(42,5 \%)$ & $122(48,6 \%)$ & $129(51,4 \%)$ & \\
\hline Idade & & & & $<0,001^{\star *}$ \\
\hline Média & 40,0 & 41,9 & 37,1 & \\
\hline Desvio padrão & 15,5 & 17,0 & 12,3 & \\
\hline Número de filhos & & & & $<0,001^{\star *}$ \\
\hline Média & 1,7 & 2,0 & 1,2 & \\
\hline Desvio padrão & 2,0 & 2,3 & 1,3 & \\
\hline Renda Familiar (salários) mínimos) & & & & $<0,001^{* *}$ \\
\hline Média & 3,5 & 3,0 & 4,1 & \\
\hline Desvio padrão & 3,1 & 3,2 & 2,8 & \\
\hline
\end{tabular}

A maioria da amostra (52,5\%) possuía parceiro, sendo observado dentro deste grupo que $44,2 \%$ possuíam conhecimento sobre o assunto (valor-p =0,033).

Os indivíduos que utilizavam o serviço de saúde pública $(57,5 \%)$ eram a maioria, mas houve menor proporção dos que conheciam a respeito do vírus $(31,8 \%)$ (valor-p $<0,001)$.

As médias de idade e número de filhos foram mais elevadas entre os entrevistados que não relataram conhecer sobre HPV, enquanto a média da renda foi maior entre aqueles que declararam ter conhecimento sobre o vírus. Essas diferenças também foram estatisticamente significativas (valor-p $<0,001$ ).
De acordo com a Tabela 3, menos da metade dos entrevistados declarou saber da existência de vacina contra o HPV (49,7\%). Entretanto, dentre eles, a maioria $(56,5 \%)$ conhecia sobre o HPV, enquanto dos que não sabiam a respeito da vacina, apenas $23,9 \%$ relataram conhecer sobre o vírus (valor-p $<0,001$ ).

A maior parte dos indivíduos questionados (54,8\%) desconhecia campanhas de HPV, mas os resultados demonstraram que o conhecimento sobre o tema foi maior dentre aqueles que já haviam visto ou ouvido alguma campanha relacionada ao assunto $(64,8 \%)$ (valor-p $<0,001)$.

Campanhas sobre DSTs já tinham sido vistas ou ouvidas pela maioria das pessoas entre- 
Tabela 3. Caracterização dos dados sobre prevenção na amostra total e comparados ao conhecimento relatado sobre o HPV entre moradores da cidade de Ipatinga no ano de 2014.

\begin{tabular}{|c|c|c|c|c|}
\hline & \multirow{2}{*}{$\begin{array}{l}\text { Frequência } \\
\qquad \%)\end{array}$} & \multicolumn{2}{|c|}{ Você sabe o que é HPV? } & \multirow{2}{*}{ Valor-p } \\
\hline & & Não & Sim & \\
\hline Existe vacina contra o HPV? & & & & $<0,001^{\star}$ \\
\hline $\operatorname{Sim}$ & $294(49,7 \%)$ & $128(43,5 \%)$ & $166(56,5 \%)$ & \\
\hline Não Sabe & $297(50,3 \%)$ & $226(76,1 \%)$ & $71(23,9 \%)$ & \\
\hline $\begin{array}{l}\text { Já viu ou ouviu sobre alguma campanha de } \\
\text { HPV? }\end{array}$ & & & & $<0,001^{*}$ \\
\hline Não & $324(54,8 \%)$ & $260(80,2 \%)$ & $64(19,8 \%)$ & \\
\hline Sim & $267(45,2 \%)$ & $94(35,2 \%)$ & $173(64,8 \%)$ & \\
\hline $\begin{array}{l}\text { Já viu ou ouviu sobre alguma campanha de } \\
\text { DST (Doença Sexualmente Transmissível)? }\end{array}$ & & & & $<0,001^{\star}$ \\
\hline Não & $132(22,3 \%)$ & $101(76,5 \%)$ & $31(23,5 \%)$ & \\
\hline Sim & $459(77,7 \%)$ & $253(55,1 \%)$ & $206(44,9 \%)$ & \\
\hline Usa camisinha nas relações sexuais? & & & & $0,698^{*}$ \\
\hline Não & $302(51,1 \%)$ & $178(58,9 \%)$ & $124(41,1 \%)$ & \\
\hline Às Vezes & $81(13,7 \%)$ & $48(59,3 \%)$ & $33(40,7 \%)$ & \\
\hline Sempre & $121(20,5 \%)$ & $74(61,2 \%)$ & $47(38,8 \%)$ & \\
\hline Não tem vida sexual. Mas usaria. & $64(10,8 \%)$ & $37(57,8 \%)$ & $27(42,2 \%)$ & \\
\hline Não tem vida sexual. Mas não usaria. & $23(3,9 \%)$ & $17(73,9 \%)$ & $6(26,1 \%)$ & \\
\hline Já fez exame preventivo? (Apenas mulheres) & & & & $0,002^{*}$ \\
\hline Não & $49(15,9 \%)$ & $36(73,5 \%)$ & $13(26,5 \%)$ & \\
\hline Sim & $260(84,1 \%)$ & $128(49,2 \%)$ & $132(50,8 \%)$ & \\
\hline
\end{tabular}

*Teste qui-quadrado.

vistadas $(77,7 \%)$. Este grupo apresentou maior proporção dos que relataram ter conhecimento sobre o HPV (valor-p < 0,001).

Mais da metade $(51,1 \%)$ dos que responderam ao questionário declararam não fazer uso de preservativos nas relações sexuais, sendo que o usar ou não o preservativo nas relações sexuais não interferiu significativamente no conhecimento sobre HPV, já que esse conhecimento variou entre $38,8 \%$ para aqueles que usam a camisinha sempre e $41,1 \%$ para os que não usam (valor-p = 0,698).

Com relação ao exame preventivo, grande parte das mulheres entrevistadas $(84,1 \%)$ disse já ter realizado o exame e, entre elas, 50,8\% conheciam sobre o vírus, enquanto entre as que nunca realizaram o exame, esse percentual foi de apenas $26,5 \%$ (valor-p $=0,002$ ).

De acordo com a análise multivariada (Tabela 4), os fatores associados ao relato de conhecimento sobre HPV foram ser do gênero feminino, ter escolaridade média ou superior, ter ouvido falar de campanha sobre HPV e saber da existência da vacina para HPV. Pode-se afirmar que quem é do gênero feminino tem 1,69 vezes mais chance de conhecer sobre o HPV que o gênero oposto.
A chance de ter esse conhecimento é 1,61 vezes maior se a pessoa frequenta um serviço de saúde particular comparado com quem frequenta o serviço público. Ter nível de escolaridade elevado interfere significativamente (valor- $p<0,001$ ) no conhecimento, já que quem tem o ensino superior possui 3,59 vezes mais chance comparado a quem possui apenas o ensino fundamental. Quem já viu ou ouviu alguma campanha sobre HPV demostra uma probabilidade 4,5 maior de conhecer sobre o HPV comparado com quem nunca viu, e saber sobre a existência da vacina também aumenta em 2,19 vezes a chance de saber sobre o vírus.

\section{Discussão}

A maior parte dos entrevistados relatou não saber o que é o HPV, sendo que esse conhecimento foi ainda menor entre homens, pessoas que utilizavam o serviço de saúde pública, com baixa escolaridade, que nunca ouviram falar de campanha sobre o vírus e que não sabem da existência da vacina contra HPV.

Mensurar o grau de conhecimento da população sobre o HPV é importante, uma vez que 
Tabela 4. Análise multivariada (regressão logística binária) avaliando os fatores associados à afirmação sobre conhecer o HPV entre moradores da cidade de Ipatinga no ano de 2014.

\begin{tabular}{lcccc}
\hline & \multirow{2}{*}{ Valor-p } & OR & \multicolumn{2}{c}{ IC 95\% } \\
\cline { 4 - 5 } & & & Limite inferior Limite superior \\
\hline Sexo & & 1,00 & - & - \\
$\quad$ Masculino & 0,009 & 1,69 & 1,14 & 2,51 \\
$\quad$ Feminino & & & & - \\
Serviço & & 1,00 & - & 2,41 \\
$\quad$ Público & 0,021 & 1,61 & 1,08 & - \\
$\quad$ Particular & & & & 3,21 \\
Escolaridade & & 1,00 & - & 6,62 \\
$\quad$ Até fundamental & 0,004 & 2,01 & 1,25 & - \\
$\quad$ Médio & $<0,001$ & 3,59 & 1,95 & 6,78 \\
$\quad$ Superior & & & & - \\
Já viu ou ouviu sobre alguma campanha de DST & & 1,00 & - & - \\
$\quad$ Não & $<0,001$ & 4,50 & 2,99 & 3,31 \\
$\quad$ Sim & & & & - \\
Existe vacina contra o HPV? & & 1,00 & 1,45 & \\
$\quad$ Não & & & \\
$\quad$ Sim
\end{tabular}

OR = Odds RatioIC95\% = Intervalo de 95\% de Confiança.

permite, via resultados obtidos, avaliar e selecionar as estratégias adequadas para que sejam construídos planejamentos eficazes com medidas de promoção, prevenção e diagnóstico precoce das alterações provocadas pelo vírus. A relevância do assunto possibilitou que diversos estudos fossem realizados no mundo, com o objetivo de verificar esse conhecimento nas populações em geral. Os achados deste estudo corroboram os descritos na literatura, como, por exemplo, Francis et al. ${ }^{20}$, que avaliaram o conhecimento acerca do HPV em um grupo de mulheres na cidade de Johanesburgo, África do Sul, e verificaram que a maioria delas não estava familiarizada com o $\mathrm{HPV}$; e Ramada e Medeiros ${ }^{21}$, que, pesquisando estudantes da Universidade do Porto, Portugal, observou que 55,4\% deles já ouviram falar sobre HPV, ressaltando que esse número pode ter ultrapassado a metade da amostra pelo fato de que esta, em sua maior parte, era composta por universitários da área da saúde. No Brasil, Osis et al. ${ }^{19}$ evidenciaram que menos da metade da população estudada (40\%) relatou já ter ouvido sobre o HPV, e ainda que pouco mais de $1 / 4$ dos entrevistados possuía "conhecimento adequado" sobre o vírus. Em nosso estudo, após validação, encontramos que grande parte $(93,25 \%)$ possuía conhecimento mínimo, considerando apenas os entrevistados que afirmaram saber o que era HPV.
A maioria das mulheres afirmou positivamente quando questionada sobre conhecer o HPV, em comparação aos homens. Resultados semelhantes foram encontrados por Osis et al. ${ }^{19}$ que evidenciaram que $45 \%$ das mulheres por eles estudadas já tinham ouvido falar sobre o tema; e Gomez e Lince $^{12}$ verificaram um percentual maior de mulheres que conheciam sobre o vírus, quando entrevistaram um grupo de universitários na Colômbia. Comparando o conhecimento apenas entre as mulheres, observou-se que mais da metade relatou não possuir conhecimento acerca do tema, evidenciando que, apesar de o grupo feminino ter percentual superior ao masculino, ainda se percebe baixa proporção de indivíduos com informação.

Escolaridade foi uma variável que também se relacionou de forma significativa com o conhecimento sobre o HPV, porque foi observado que os entrevistados com nível superior de ensino relataram conhecer sobre o tema, enquanto dentre aqueles com nível médio de ensino, apenas um quinto revelou saber do que se tratava. Outras publicações reforçam esse achado, como, por exemplo, Santos et al. ${ }^{22}$, que demonstraram que as maiores informações a respeito do HPV pertenciam às mulheres com ensino superior; e o de Pimenta et al. ${ }^{23}$ que afirmaram que $51 \%$ das mulheres que não sabiam o que era HPV apresentavam apenas 5 a 8 anos de estudo, e dos que 
possuíam entre 9 a 11 anos de estudo, 25,9\% desconheciam sobre o HPV. Segundo Miranda et al. ${ }^{24}$, pessoas com um maior grau de estudo, apresentam também uma maior preocupação quanto a não se infectarem com alguma DST, quando comparados com um grupo de nível educacional inferior. Baseados nessa afirmação, uma hipótese que justifica os resultados encontrados é a de que indivíduos com mais tempo de estudo possuem um interesse maior em obter novos conhecimentos e têm mais acesso a fontes confiáveis de informação, como literatura científica, professores ou médicos. Outra explicação pode ser o fato de que esse grupo pode compreender de forma mais adequada os conteúdos que lhes são apresentados, por meio de televisão ou campanhas.

Dentre os meios de comunicação utilizados para a obtenção de informações sobre o vírus, a TV apresentou maior frequência de respostas, seguida pelos professores e internet, enquanto médicos e profissionais de saúde foram pouco citados:10,1\% e $12,7 \%$, respectivamente. Resultados diferentes foram relatados por Panobianco et al. ${ }^{25}$ e Pimenta et al..$^{23}$, sendo que, no primeiro, $42,9 \%$ das entrevistadas que afirmaram ter conhecimento sobre o HPV o atribuíram ao médico ginecologista e, no segundo, esse percentual foi de $45 \%$. Ressalta-se, entretanto, que no trabalho Panobianco et al. ${ }^{25}$ a sua amostra consistia de adolescentes do gênero feminino do curso de enfermagem e no de Pimenta et al..$^{23}$, as entrevistadas que receberam informações por médico, quase em sua totalidade, já haviam sido diagnosticadas com algum tipo de DST. Uma teoria para essa divergência nos resultados pode ser justificada pela campanha de vacinação contra o HPV, veiculada na televisão nos meses que antecederam a coleta de dados, e também durante o período da entrevista.

O fator econômico interferiu significativamente no conhecimento da população, já que foi possível observar, por meio de análise univariada, que os indivíduos com maior renda demonstraram possuir mais informações a respeito do vírus. Diversos autores descreveram resultados semelhantes, como, por exemplo, Oliveira et al. ${ }^{26}$, o que ressaltou a relação entre a baixa condição socioeconômica e a infecção pelo HPV, atribuindo esse achado ao fato de que a baixa renda familiar dificulta o acesso ao conhecimento sobre esse tema. Um estudo realizado com usuários de unidades básicas de saúde (UBS) e duas policlínicas do SUS de Campinas-SP, em 2011, 46\% das pessoas entrevistadas que pertenciam aos estratos socioeconômicos A e B responderam ter ouvido falar sobre o HPV, enquanto apenas 33,1\% das classes $\mathrm{C}$ e $\mathrm{D}$ relataram possuir conhecimento sobre esse assunto. Conti et al. ${ }^{27}$, quando avaliaram alunos de colégios particular e público, acerca do conhecimento que possuíam sobre o HPV, concluíram que os estudantes do colégio particular demonstraram maior conhecimento sobre o HPV quando comparados aos do colégio público. Uma hipótese que possa justificar esses resultados se deve, dentre outros fatores, ao fato de classes economicamente desfavorecidas terem menor acesso aos serviços de saúde, além de ser também essa classe a que enfrenta maiores dificuldades financeiras para dar seguimento ao tratamento, quando necessário, associado ao desconhecimento das medidas de promoção da saúde e prevenção da doença, como relatado por Eduardo et al. ${ }^{28}$.

De acordo com o serviço de saúde utilizado pelo entrevistado, verificou-se que mais da metade dos usuários do setor privado relataram conhecer sobre o HPV, enquanto dentre as pessoas utilizadoras do serviço público esse relato foi menor que $1 / 3$. Corroborando esse resultado, Osis et al. ${ }^{19}$ afirmaram que menos de $2 / 5$ dos usuários do SUS entrevistados em seu trabalho responderam já terem ouvido falar sobre o HPV. De acordo com a pesquisa de Ribeiro et al..$^{29}$, as características da clientela atendida pelo SUS era de indivíduos adultos de 15 a 49 anos, de ambos os sexos, de cor preta ou parda, com escolaridade inferior a 11 anos e renda familiar per capita inferior a R \$ 440,00 mensais. Diante disso, os resultados obtidos podem ser justificados, já que esse perfil corrobora os resultados das variáveis escolaridade e renda já analisadas anteriormente e, ainda, segundo Prado e Santos ${ }^{30}$, existe elevado grau de desigualdade social entre os diferentes segmentos da população com relação ao acesso aos serviços de saúde.

$\mathrm{Na}$ análise univariada, observou-se, significativamente, que a média de idade da população que referiu conhecimento acerca do HPV era mais elevada do que aquela encontrada entre a população que referiu não conhecer. De acordo com Pimenta et al. ${ }^{23}$, proporções mais altas de conhecimentos e atitudes mais adequadas parecem estar associadas a idade maior ou igual a 35 anos, sendo que a média foi de 31,3 anos. Em outro estudo, que avaliou estudantes de universidade pública de Manizales, $31 \%$ daqueles com idades entre 28 e 35 anos apresentaram alto conhecimento sobre o HPV, contudo, $65 \%$ da amostra possuíam entre 17 a 20 anos $^{12}$.

Em se tratando do número de filhos, a média foi mais elevada entre os entrevistados que rela- 
taram não conhecer sobre o HPV. Resultado semelhante foi relatado por Osis et al. ${ }^{19}$ e Pedregosa et al. ${ }^{31}$, que destacam ser a multiparidade um dos fatores de risco coadjuvantes identificados, que contribuem para o desenvolvimento do câncer de colo de útero. Entretanto, é possível verificar que a variável número de filhos nos estudos está, na maior parte das vezes, associada também à baixa escolaridade, como descrito por Moura et al. ${ }^{32}$, que relataram que mulheres de menor escolaridade tendem a ter maior número de partos do que aquelas com maiores anos de estudos (valor $\mathrm{p}=0,045)$. Dessa forma, é possível supor que o fato do número de filhos ter influenciado no conhecimento sobre o tema está mais relacionado aos fatores escolaridade e renda do que se essa variável for analisada de forma independente, assim como pode ser comprovado com os resultados da análise multivariada.

O exame preventivo não identifica o vírus, mas é capaz de detectar alterações celulares induzidas pelo HPV, que são patognomônicas, denominadas coilocitose (consistindo de atipia nuclear e vacuolização perinuclear), e detecta também o carcinoma espinocelular, daí a importância de sua realização periódica ${ }^{33}$. O percentual de mulheres que haviam realizado o exame preventivo de acordo com o presente estudo foi elevado $(84,1 \%)$. Entretanto, esse valor assemelha-se com os resultados apresentados pela PNAD (Pesquisa Nacional por Amostra de Domicílios) realizada pelo IBGE (Instituto Brasileiro de Geografia e Estatística) para o ano de 2008. Segundo dados da PNAD, no Brasil 84,5\% das mulheres (com 25 anos ou mais) já haviam realizado o preventivo, sendo que na região Sudeste, esse percentual foi de $87,6 \%{ }^{34}$. A realização do preventivo interferiu positivamente no conhecimento sobre HPV, pois a maioria das mulheres que já havia realizado o exame afirmou saber sobre o vírus (50,8\%). Entretanto ainda é preocupante, pois dentre as que já haviam realizado o exame o percentual de desconhecimento sobre o vírus foi próximo de $50 \%$. $\mathrm{O}$ estudo de Santos et al. ${ }^{22}$ demonstrou que apenas $11 \%$ dentre as mulheres, com exame preventivo já realizado, relataram desconhecimento do objetivo do exame; Cirino et al. ${ }^{35}$ observaram que dentre os seus pesquisados esse percentual era de $43,5 \%$.

Quando questionados sobre a existência de vacina contra o HPV, pouco menos da metade dos entrevistados afirmou saber de sua existência e, dentre eles, a maioria afirmou ter conhecimento a respeito do vírus. Não foram encontrados na literatura estudos que correlacionassem o co- nhecimento sobre HPV com saber da existência da vacina. Todavia verifica-se no estudo de Osis et al. ${ }^{19}$ que, dentre aqueles que já ouviram falar sobre a vacina, a maioria era de mulheres, maiores de 25 anos, apresentando mais de 9 anos de estudo, e pertencente aos estratos econômicos A e B. Uma hipótese que pode também justificar esse achado seria a de que o Ministério da Saúde, em 2014, introduziu em seu calendário a vacina contra o HPV para meninas entre 11 e 13 anos e veiculou uma campanha na televisão, o que, de certa forma, pode ter ampliado o conhecimento da população sobre a vacina, mas não sobre o vírus, uma vez que dentre os que sabiam da existência da mesma ainda era grande o percentual de desconhecimento a respeito do vírus $(43,5 \%)$.

Segundo Santos e Assis ${ }^{36}$, mesmo quando as campanhas sobre DSTs atingem uma boa parcela da população, as mudanças nos hábitos e atitudes ainda são deficitárias, necessitando de maiores intervenções culturais nesses aspectos. Pimenta et al. ${ }^{23}$ observaram que $51 \%$ das mulheres entrevistadas sabiam a respeito do vírus HPV. Entretanto, a maior parte delas já havia apresentado alguma manifestação do vírus, e outra parte já havia tido o diagnóstico de alguma outra DST anteriormente; isso evidencia a importância e a necessidade de investimento em campanhas sobre DSTs, com abrangência em toda a população, em diversas épocas, e com foco nas mais variadas doenças. O primeiro relato que se tem de uma campanha de DSTs de mídia oficial ocorreu em 1995, no Carnaval, considerada a maior festa popular do mundo, festa que colabora para o aumento dos casos de Aids. Isso justificou a necessidade de realização de campanhas de prevenção especificamente nessa época ${ }^{26}$. Contudo, nota-se que essa estratégia em saúde pública é relativamente recente (cerca de 20 anos), e que o conteúdo pode ser pouco abrangente e/ou didático às campanhas.

Com relação a campanhas sobre HPV, o que se pode observar foi que menos da metade das pessoas questionadas tinham visto ou ouvido alguma campanha sobre o tema; porém, entre as que já tinham visto ou ouvido, a maioria tinha conhecimentos acerca do vírus. Segundo Santos et al. ${ }^{22}$, existe uma associação entre a manifestação de conhecimento sobre como prevenir o câncer de colo de útero e o conhecimento sobre HPV. Entretanto, conclui-se que, apesar desse conhecimento, não há grau de profundidade necessário para que aconteça prevenção eficaz. Por acaso nos programas e campanhas de prevenção do câncer de colo de útero, o foco se voltou muito 
para a necessidade de realização do exame preventivo, a fim de se ter um diagnóstico precoce de um provável câncer, sem, no entanto, divulgar informações sobre qual seria o agente causal e as características dessa infecção.

Saber o modo de transmissão do HPV poderia estabelecer novos comportamentos tanto preventivos quanto terapêuticos. Observou-se que a grande maioria dos entrevistados respondeu conhecer como ocorre a transmissão do vírus $(93,2 \%)$, sendo que quase sua totalidade $(97,3 \%)$, relatou ser sexualmente transmissível. Outras formas possíveis de propagação também foram citadas, entretanto, com uma baixa frequência. Também foram relatadas formas inadequadas de transmissão, que fogem ao espectro do HPV. Pimenta et al. ${ }^{23}$, abordando apenas mulheres, destacaram que cerca de $81,5 \%$ sabiam da transmissão sexual do HPV, corroborando ser o fator feminino como determinante no conhecimento. A respeito dos alvos possíveis de contrair a infecção (homem, mulher, criança), observou-se que houve leve predominância das respostas como sendo as mulheres, entretanto houve discrepância significativa quanto às crianças. Esse achado pode ser devido ao fato de que quase a totalidade das respostas da via de infecção foi relação sexual, havendo desconhecimento das outras vias. Bretas et al. ${ }^{37}$ relataram que a transmissão materno-fetal foi relatada por $1 \%$ dos adolescentes.

Uma limitação deste estudo é o fato de o desfecho ter sido avaliado por meio das respostas obtidas em um formulário não padronizado cientificamente, com a avaliação do conhecimento a partir da identificação do que o entrevistado já tinha ouvido falar. Isso poderia estar superestimando ou subestimando o conhecimento, o que tornaria ainda mais grave o problema. No entanto, observou-se que a maioria dos entrevistados que relatou saber o que é o HPV conhecia pelo menos uma das assertivas que indicava um conhecimento mínimo necessário sobre o vírus, o que poderia garantir que a afirmação "saber o que é o HPV" está de fato demonstrando algum conhecimento sobre o tema. Entretanto, essa tentativa de valida- ção possui limitação, já que o entrevistado poderia ter confundido, por sonoridade, com o HIV (Vírus da Imunodeficiência Humana). Em adição, trata-se de um estudo transversal que impossibilita a utilização da temporalidade como critério causal, uma vez que fatores e desfechos são vistos em um mesmo momento. Por outro lado, reforça-se a importância dessa investigação por se tratar de um inquérito com base populacional, tendo em vista que se objetivou a representatividade da cidade de Ipatinga e que, até o momento, identificamos poucos estudos brasileiros com esse nível de representatividade ${ }^{38}$.

\section{Conclusão}

Sugere-se, por meio desta pesquisa, que há um grande déficit no conhecimento a respeito do HPV e que, muitas vezes, há pouca qualificação do que se sabe, favorecendo, assim, muito além dessas percepções errôneas, ações com risco potencial à saúde, inclusive a do parceiro. Ter conhecimento de que HPV é um vírus transmitido, principalmente, por via sexual, com potencial cancerígeno, que pode ser evitado através da vacina e de medidas protetivas nas relações sexuais, e que, por meio do exame do Papanicolau, é feito o rastreio das alterações virais e do câncer de colo uterino, seria um patamar mínimo de conhecimento para a população.

Dessa forma, o desenvolvimento de estratégias voltadas para a saúde pública, com enfoque na prevenção e limitação de agravos, como a inclusão de ações visando qualificar o grau de conhecimento sobre HPV, pode ser a chave para estase do ciclo da doença. É importante ressaltar o papel fundamental do marketing na elaboração de políticas públicas, utilizando táticas que despertem tanto o interesse pelo tema quanto atinjam direta ou indiretamente um público amplo, principalmente a população destacada neste artigo com menor conhecimento sobre o tema, isto é, homens, indivíduos com baixa escolaridade e baixo nível socioeconômico. 


\section{Colaboradores}

MNS Abreu, AD Soares, DAO Ramos, FV Soares, G Nunes Filho, AF Valadão e PG Motta participaram na concepção, desenho e análise deste estudo, assim como na escrita final e assumem total responsabilidade pelos resultados apresentados. A versão final do manuscrito foi aprovada pelos autores.

\section{Referências}

1. Magi JC, Brito EMS, Grecco ETO, Pereira SMM, Formiga GJS. Prevalência de papilomavírus humano (HPV) anal, genital e oral, em ambulatório geral de coloproctologia. Rev Bras Colo-Proctol 2006; 3(26):233-238.

2. São Paulo (Estado). Instituto Nacional de Ciência e Tecnologia das Doenças do Papilomavírus Humano. Entenda de vez os papilomavírus humanos, as doenças que causam e o que já é possivel fazer para evitá-los. Guia do HPV. São Paulo, 2013. [acessado 19 jun. 2015 Jun 19]. Disponível em: http://www.incthpv.org.br/upl/ fckUploads/file/Guia\%20do\%20HPV\%20Julho\%20 2013_2.pdf

3. Fedrizzi EN. Epidemiologia da infecção genital pelo HPV. Rev Bras Pat Trato Gen Inf 2011; 1(1):3-8.

4. Federação Brasileira das Sociedades de Ginecologia e Obstetrícia. Projeto diretrizes: Papilomavírus Humano (HPV): Diagnóstico e Tratamento. 2002. [acessado 2015 Mar 3]. Disponível em: http://www.febrasgo.org.br/arquivos/diretrizes/079.pdf

5. Rosenblatt C, Lucon AM, Pereyra EAG, Pinnotti JA, Arap S. Papilomavírus humano em homens: "triar ou não triar” - uma revisão. Einstein 2004; 2(3):212-216.

6. Mendonça ML, Netto JCA. Importância da infecção pelo papilomavírus humano em pacientes do sexo masculino. DST J Bras Doenças Sex Transm 2005; 17(4):306-310.

7. Castellsagué X, Bosch FX, Muñoz N. Environmental co-factors in HPV carcinogenesis. Virus Res 2002; 89(2):191-199.

8. Nadal SR, Manzione CR. Papilomavírus humano e o câncer anal. Rev Bras Colo-proctol 2006; 26(2):204-207.

9. Fuente Diez E, Ferrer LMM. Las 47 preguntas sobre el vírus del papiloma humano, VPH. Med Segur Trab 2008; 54(212):111-119.

10. Chaves JHB, Vieira TKB, Ramos JS, Bezerra AFS. Peniscopia no rastreamento das lesões induzidas pelo papilomavírus humano. Rev Bras Clin Med 2011; 9(1):3035.

11. Costa LA, Goldenberg P. Papilomavírus Humano (HPV) entre Jovens: um sinal de alerta. Saúde Soc 2013; 22(1):249-261.

12. Gomez ML, Lince L. Conocimientos que tienen los estudiantes de una universidad publica de Manizales sobre el papillomavirus humano. Hacia la Promoción de la Salud 2011; 16(1):110-123.

13. Vargens OMC, Silva CM, Silva GA, Girianelli VR. Diagnóstico de HPV: o processo de interação da mulher com seu parceiro. Rev Bras Enf 2013; 66(3):327-332.

14. Castro-Vasquez MC, Arellano-Galvez MC. Acesso a la información de mujeres com VPH, displasia e cáncer cervical in situ. Salud Pública de México 2010; 52(3):207-212.

15. Urrutia MT, Concha X, Riquelme X, Padilla O. Conocimientos y conductas preventivas sobre câncer cérvico-uterino y virus papiloma humano em un grupo de adolescentes chilenas. Rev Chi Infectol 2012; 29(6):600606.

16. Instituto Brasileiro de Geografia e Estatística (IBGE). Atlas do censo demográfico 2010. [acessado $2015 \mathrm{Mar}$ 11]. Disponível em: www.cidades.ibge.gov.br

17. Prefeitura Municipal de Ipatinga. História da cidade. [acessado 2015 Mar 13]. Disponível em: www.ipatinga. mg.gov.br. 
18. Babbie E. Survey research methods. $10^{\text {th }}$ ed. Belmont: Wadsworth Publishing; 2004.

19. Osis MJD, Duarte GA, Sousa MH. Conhecimento e atitude de usuários do SUS sobre o HPV e as vacinas disponíveis no Brasil. Rev Saude Publica 2014; 48(1):123133.

20. Francis SA, Nelson J, Liverpool J, Soogun S, Mofammere N, Thorpe Junior RJ . Examining attitudes and knowledge about HPV and cervical cancer risk among female clinic attendees in Johannesburg, South Africa. Vaccine 2010; 28(50):8026-8032.

21. Ramada D, Medeiros R. HPV e cancro do colo do útero: intervenção urgente. Onco-news - Associação de Enfermagem Oncologica Portuguesa 2007; 2:4-7.

22. Santos A, Macedo A, Mota M, Moutinho J, Francisca A, Silva DP. Avaliação de conhecimentos e comportamentos das mulheres relativos à prevenção ginecológica em Portugal. Acta Obstet Ginecol Port 2008; 2(2):65-71.

23. Pimenta ATM, Melli PPS, Duarte G, Quintana SM. Conhecimento de mulheres sobre alguns aspectos do papiloma vírus humano. Revista de Medicina (Ribeirão Preto) 2014; 47(2):143-148.

24. Miranda AE, Ribeiro D, Rezende EF, Pereira GFM, Pinto VM, Saraceni V. Associação de conhecimento sobre DST e grau de escolaridade entre conscritos em alistamento ao Exército Brasileiro. Brasil, 2007. Cien Saude Colet 2013; 18(2):489-497.

25. Panobianco MS, Lima ADF, Oliveira ISB, Gozzo TO. O conhecimento sobre o HPV entre adolescentes estudantes de graduação em enfermagem. Texto Contexto Enferm 2013; 22(1):201-207.

26. Oliveira RG, Magalhães SR, Lima KP, Frota NM. Aspectos sociodemográficos e ginecológicos de mulheres com neoplasia intraepitelial cervical de baixo grau. Rev Enferm UFPE 2014; 8(4):1002-1010.

27. Conti FS, Bortolin SB, Kulkamp IC. Educação e promoção à saúde: Comportamento e conhecimento de adolescentes de colégio público e particular em relação ao Papiloma Virus Humano. J Bras Doenças Sex Trans 2006; 18(1):30-35.

28. Eduardo KGT, Moura ERJ, Nogueira PSF. Conhecimento e mudanças de comportamento de mulheres junto a fatores de risco para câncer de colo uterino. Rev Rene 2012; 13(5):1045-1055.

29. Ribeiro MCSA, Barata RB, Almeida MF, Silva ZP. Perfil sociodemográfico e padrão de utilização de serviços de saúde para usuários e não usuários do SUS - PNAD 2003. Cien Saude Colet 2006; 11(4):1011-1022.

30. Prado DS, Santos DL. Contracepção em usuárias dos setores público e privado de saúde. Rev Bras Ginecol Obst 2011; 33(7):143-49.
31. Pedregosa JF, Rodrigues, DA, Munhoz NG, Pandossio T, Rodrigues JO, Junqueira MSG, Yonamine PTK, Pereira SF, Uezato S, Carvalho DAT, Cury PM, Bonilha JL. Perfil sócio-econômico-cultural e fatores de risco em pacientes com neoplasia intra-epitelial cervical persistente. Arq Ciênc Saúde 2010; 17(1):42-47.

32. Moura EJ, Silva RM, Gomes AMA. Perfil demográfico, socioeconômico e de saúde reprodutiva de mulheres atendidas em planejamento familiar no interior do Ceará. Rev Baiana de Saúde Pública 2010; 34(1):119-133.

33. Xavier SD, Bussoloti Filho I, Lancellotti CLP. Prevalência de achados sugestivos de papilomavírus humano (HPV) em biópsias de carcinoma espinocelular de cavidade oral e orofaringe: estudo preliminar. Rev Bra Otorrinolaringol 2005; 71(4):510-519.

34. Instituto Brasileiro de Geografia e Estatística (IBGE). Pesquisa Nacional por amostra de domicílios 2008 (PNAD). [acessado 2015 Mar 16]. Disponível em: http://tabnet.datasus.gov.br/tabdata/LivroIDB/2edrev/ f22.pdf

35. Cirino FMSB, Nichiata LYI, Borges ALV. Conhecimento, atitudes e praticas na prevenção do câncer de colo de útero e HPV em adolescentes. Esc Anna Nery Rer Enferm 2010; 14(1):126-134.

36. Santos AFM, Assis M. Vulnerabilidade das idosas ao HIV/Aids: despertar das políticas públicas e profissionais de saúde no contexto da atenção integral: revisão de literatura. Rev Bras Geriatr Gerontol 2011; 14(1):147-157.

37. Bretas JRS, Ohara CVS, Jardim DP, Muroya RL. Conhecimento sobre DST/AIDS por estudantes adolescentes. Rev Esc Enferm USP 2009; 43(3):551-557.

38. Brasil. Ministério da Saúde (MS). PCAP: Pesquisa de Conhecimentos, Atitudes e Práticas na População Brasileira, 2008. Brasília: MS; 2011.

Artigo apresentado em 04/01/2016

Aprovado em 15/06/2016

Versão final apresentada em 17/06/2016 